\title{
Temporal relationship of conduction system disease and ventricular dysfunction in LMNA cardiomyopathy
}

\author{
Chad Brodt, MD ${ }^{1}$, Jill D. Siegfried, MS, CGC ${ }^{1}$, Mark Hofmeyer, MD¹, Jose Martel, MD1, \\ Evadnie Rampersaud, PhD $^{2}$, Duanxiang Li, MD, MS ${ }^{1}$, Ana Morales, MS, CGC $^{1}$, and Ray E. \\ Hershberger, MD ${ }^{1}$ \\ ${ }^{1}$ Cardiovascular Division, University of Miami Miller School of Medicine, Miami, FL \\ ${ }^{2}$ Hussman Institute for Human Genomics, University of Miami Miller School of Medicine, Miami, \\ $\mathrm{FL}$
}

\begin{abstract}
Background-LMNA cardiomyopathy presents with ECG abnormalities, conduction system disease (CSD) and/or arrhythmias prior to the onset of dilated cardiomyopathy (DCM). The time interval between the onset of CSD and its progression to DCM, if known, would help to guide clinical care.
\end{abstract}

Methods and Results-We evaluated family members from 16 pedigrees previously identified to carry $L M N A$ mutations for the ages of onset of ECG abnormalities, CSD or arrhythmia, and of left ventricular enlargement (LVE), systolic dysfunction or both. Of 103 subjects, 64 carried their family $L M N A$ mutation, and 51 (79\%) had ECG abnormalities with a mean age of onset of 41.2 years (range 18-76). Ventricular dysfunction was observed in 26 with a mean age of onset of 47.6 (range 28-82); at diagnosis 9 had systolic dysfunction but no LVE, 5 had LVE but no systolic dysfunction, and 11 had DCM. Of 16 subjects identified with ECG abnormalities who later developed ventricular dysfunction, the median ages of onset by log rank analyses were 41 and 48 years, respectively.

Conclusions-ECG abnormalities preceded DCM with a median difference of seven years. Clinical surveillance should occur at least annually in those at risk for LMNA cardiomyopathy with any ECG findings.

\section{Introduction}

Dilated cardiomyopathy (DCM) from non-ischemic cause is a common form of cardiomyopathy. In those cases where any detectable cause (except genetic) have been excluded, the conventional diagnosis has been idiopathic dilated cardiomyopathy (IDC). Extensive family studies of patients with IDC (as comprehensively reviewed ${ }^{1}$ ) have shown that $20-35 \%$ will have detectable family disease. Of these who have been found to have familial DCM, a great deal of work over the past 15 years has shown that familial DCM has

() 2013 Elsevier Inc. All rights reserved.

Address for correspondence: Ray E. Hershberger, MD, Davis Heart and Lung Research Institute, Room 304, The Ohio State University College of Medicine, 460 West 12th Avenue, Columbus, OH 43210. Phone: 614-688-1305; Fax 614-688-1381; Ray.Hershberger@osumc.edu.

Publisher's Disclaimer: This is a PDF file of an unedited manuscript that has been accepted for publication. As a service to our customers we are providing this early version of the manuscript. The manuscript will undergo copyediting, typesetting, and review of the resulting proof before it is published in its final citable form. Please note that during the production process errors may be discovered which could affect the content, and all legal disclaimers that apply to the journal pertain.

Disclosures: None. 
been linked to mutations in over 30 genes, establishing genetic cause as key. ${ }^{2}$ One of these genes is $L M N A$, which encodes the nuclear envelope proteins lamin A and lamin C. ${ }^{2}$ Numerous studies ( $\mathrm{see}^{2}$ for numerous earlier references) including two large European consortium reports ${ }^{3,4}$ have illustrated that DCM, heart failure and lethal arrhythmias usually present following ECG abnormalities. However, the time course from the onset of ECG abnormalities, CSD and arrhythmia to DCM has not been evaluated in any of these prior studies.

This is relevant as next generation sequencing methods have brought about the rapid proliferation of clinical genetic testing, and recent guidelines have suggested that with the symptom complex of prominent conduction system disease and early signs of DCM, usually with supraventricular or ventricular arrhythmias, that genetic testing for $L M N A$ rare variants should be considered. ${ }^{5-7}$ This is especially relevant for identifying mutations in $L M N A$ because of the temporal relationship of CSD and the onset of DCM. While no clinical trials have been conducted in $L M N A$ cardiomyopathy to show that early drug intervention may slow or halt progression to full blown DCM, advanced heart failure and lethal ventricular arrhythmias, anecdotal evidence suggests that conventional medical therapy may slow disease progression. Extensive work is also in progress to develop investigational agents specific for the laminopathies, including $L M N A$ cardiomyopathy ${ }^{8}$ and for the most severe laminopathy, progeria. ${ }^{9}$ Hence, further knowledge of the temporal relationships of early to late disease may be useful for clinical care and for clinical trial design. To this end, we undertook an analysis of the 16 of 19 families previously reported from our group ${ }^{10-12}$ containing 103 subjects in our familial dilated cardiomyopathy (FDC) cohort, 64 with $L M N A$ mutations, for the temporal relationships of these characteristics.

\section{Methods}

\section{Clinical analysis}

As previously described, written, informed consent was obtained from probands and their family members, and the family medical history was obtained, a pedigree was constructed, and a blood sample was obtained for genetic research. ${ }^{12,13}$ The study was approved by the Institutional Review Boards at the Oregon Health \& Science University and the University of Miami Miller School of Medicine.

LMNA rare variant mutation carriers from 16 of the previously identified 19 families (Pedigrees A-S, as previously published ${ }^{12}$ ) were analyzed in this study (Table I). Three pedigrees (L, N, R) were excluded due to confounding gene mutations: Family $\mathrm{N}$ due to a known $R B M 2 O$ rare variant also segregating in many of its members; ${ }^{14}$ Pedigree $\mathrm{R}$ because of a known TCAP rare variant in its one $L M N A$ mutation carrier; ${ }^{15}$ and Pedigree $\mathrm{L}$ with its single $L M N A$ mutation carrier ${ }^{12}$ because of a possible second rare variant. In Pedigree $\mathrm{S}$, only two subjects, S.5 and S.6, were included; the two other $L M N A$ mutation carriers (S.9, S.11) were excluded because of their possible inheritance of a maternally transmitted DCM rare variant. ${ }^{12}$

Clinical data, including ECGs and echocardiograms, were obtained and evaluated from multiple sources, including our own cardiovascular clinical screening data that included ECG's and echocardiograms for some families, as previously reported, ${ }^{10,11}$ or additional information from medical records or death certificates using our previously published research protocols. ${ }^{10-13}$ All data were entered in Progeny (Delray Beach, FL), a relational database designed for family-based genetic studies.

Dilated cardiomyopathy (DCM) was defined as LV enlargement (LVE) $>95 \%$ percentile based on age- and gender-matched population controls from the Framingham study, ${ }^{16}$ (as 
indicated by the $\mathrm{Z}$ score denoting the units of standard deviation, as previously applied in our studies ${ }^{13}$ ) and systolic dysfunction (left ventricular ejection fraction (LVEF) $\leq 50 \%$ ); individuals with coronary artery disease, primary valvular dysfunction, congenital heart disease, hemochromatosis, toxic or drug-induced cardiomyopathies or any other potential cause of non-genetic cardiomyopathy were excluded from analysis. ${ }^{13,17}$

ECG abnormalities were divided into three categories: sinoatrial disease, His/bundle disease, and arrhythmias. Sinoatrial disease was defined as first, second or third degree atrioventricular block, sinus node dysfunction including severe bradycardia, the brady-tachy syndrome, or the requirement for a permanent pacemaker (PPM). His bundle disease was defined as any incomplete bundle branch block (iBBB), right bundle branch block (RBBB), left bundle branch block (LBBB) or intraventricular conduction delay (IVCD). Arrhythmias were defined as atrial flutter or atrial fibrillation (AF), supraventricular tachyarrhythmias (SVT), premature atrial contractions or premature ventricular contractions (PAC/PVC), ventricular tachycardia or ventricular fibrillation (VT/VF), and sudden cardiac death (SCD). Those receiving an implantable cardioverter-defibrillator (ICD) were also noted.

A subset of 16 of the 64 mutation positive individuals were identified that were known to have ECG abnormalities at a specified age without concurrent LV dysfunction and subsequently went on to develop LV dysfunction. This subset underwent further analysis for the time interval between the identification of ECG abnormalities and the development of any $\mathrm{LV}$ dysfunction. These 16 individuals came from 11 pedigrees, one each from pedigrees A, B, D, H, I, M, S, two each from C, G and P, and three from J.

\section{Genetic analysis}

LMNA molecular genetic analysis for these probands and pedigrees has been previously reported. ${ }^{10-12}$ DNA was extracted from whole blood, and all exons and intron/exon boundaries were PCR amplified and sequenced by standard methods in our laboratory. ${ }^{12,} 18$ Many of these $L M N A$ rare variants have been subjected to functional studies by assessing morphological variation in lamin $\mathrm{A} / \mathrm{C}$ nuclear localization. ${ }^{19}$ As previously reported, to exclude possible confounding effects the rare variants of 15 other genes were excluded in the probands of each family in our laboratory ${ }^{14,18,20}$ or at SeattleSNPs under contract to the NHLBI resequencing and Genotyping Service. ${ }^{15,21}$ Individuals who were obligate carriers of the family's $L M N A$ mutation by pedigree analysis were included in the analysis when medical records were available.

\section{Statistical analysis}

All data points are presented as mean values, standard deviation and range. T-tests were performed using the SISA (Simple Interactive Statistical Analysis; http:// www.quantitativeskills.com/sisa/index.htm) website. Log-rank tests were used to compare differences between age of first detection of any ECG and age at first detection of any left ventricular dysfunction (LVE, systolic dysfunction, or DCM). Analyses were performed using SAS version 9.2 (SAS Institute Inc, Cary, North Carolina). Hypotheses were not specified a priori, and P-values are provided as an indication of relative strength of association.

\section{Results}

\section{Baseline characteristics}

The demographic and clinical characteristics of the 103 subjects from 16 pedigrees included in this analysis are shown (Table II). Sixty-four of the 103 had $L M N A$ mutations identified by DNA Sanger molecular sequencing $(\mathrm{n}=56)$ or by analysis of family pedigrees as obligate 
carriers $(\mathrm{n}=8)$. The remaining 39 family members had $L M N A$ rare variants excluded by Sanger sequencing.

The wide range of first available cardiovascular data (Table II) was driven in part by our onsite research screening of two very large families, as previously reported. ${ }^{10}$ No evidence of any $L M N A$-related syndromic disease (e.g., skeletal muscle disease, lipodystrophy, or other manifestations of extra-cardiac laminopathy ${ }^{22}$ ) was observed in any of the subjects carrying $L M N A$ mutations.

\section{ECG abnormalities}

ECG abnormalities were present in 51 of 64 (79\%) of subjects with $L M N A$ mutations, with the first abnormality detected at an age ranging from 18-76 years (Table III). Of the 64 with mutations, $13(18 \%)$ had two or more ECG abnormalities at first evaluable data at a mean of 46.1 years compared to only 2 of the 39 individuals in the mutation negative group (Table III).

\section{Sinoatrial disease}

A diagnosis of sinoatrial disease could be made in 35 individuals from the mutation positive group (Table III), and of these, 15 individuals presented initially with sinoatrial disease only. Only 3 individuals in the mutation negative group had findings of sinoatrial dysfunction, two with first degree AV block, and a third by medical records of AV block not otherwise specified. The t-test comparing age of detection of sinoatrial findings among mutation positive versus negative groups was nominally significant $(\mathrm{p}=0.0198)$ A permanent pacemaker was placed in 27 mutation positive individuals identified with sinoatrial dysfunction (Table III), ranging in age from 31-69 years. Only one subject, age 62, required a pacemaker in the mutation negative group.

\section{Arrhythmia}

A diagnosis of any arrhythmia was made in 41 mutation positive subjects at an average age of 45.1 years (range, 25-76). Supraventricular arrhythmias make up the majority of cases when compared with ventricular abnormalities (Table III). Six individuals negative for a $L M N A$ mutation were observed to have any arrhythmias at an average age of 41.7 years; these included combinations of atrial fibrillation/flutter, supraventricular tachycardias, premature atrial or ventricular contractions, and one with ventricular tachycardia at 72 years that did not require an ICD. Age of detection of arrhythmia was statistically different between mutation positive and negative individuals $(\mathrm{p}=0.0028)$.

\section{His bundle disease}

In 14 subjects with $L M N A$ mutations, His bundle disease was observed at ages ranging from 18-76 years (average 43.6 years); in 4 with these findings no other cardiac abnormalities were identified.

\section{Ventricular dysfunction}

The ventricular dysfunction data, here meaning LVE, systolic dysfunction, or both (DCM) are summarized (Table IV), and were observed in 26 of the $L M N A$ mutation positive group. We note that of the 26 with ventricular dysfunction, only three did not have an accompanying abnormal ECG. However, two of these three individuals eventually developed ECG abnormalities while the third had no evidence of ECG abnormality 10 years after the initial diagnosis of DCM at age 31 . 
Nine individuals were identified with systolic dysfunction only but no LVE (mean age 47.9 years, range, 31-82), and 5 subjects presented with LVE but had no systolic dysfunction (mean age, 43.4 years, range, 35-51). Eleven individuals had DCM (systolic dysfunction and LVE) at diagnosis (mean 48.7 years, range 28-64).

In those diagnosed with systolic dysfunction but no LVE, moderate reduction in the LVEF was observed (mean LVEF of 38.1\%). In those diagnosed with LVE and preserved systolic function, the LV size was moderately enlarged (mean $\mathrm{Z}$ score of 3.49).

\section{Age of detection of ECG abnormalities or arrhythmias}

The age-dependent onset of abnormalities in the subjects with $L M N A$ mutations is shown (Figure 1), with the age of detection of any ECG or arrhythmia, and the age of detection of sinoatrial or His bundle disease between 30-60 years. Because of our study design, which did not have structured ECGs obtained at set intervals (e.g., an annual basis), only the age of detection can be reported rather than the age of onset.

\section{Age of detection of ventricular dysfunction}

The age-dependent onset of ventricular dysfunction is shown (Figure 2). The ages of detection of LVE without systolic dysfunction was censored when systolic dysfunction was detected, and the ages of detection of systolic dysfunction without LVE was censored when LVE became apparent. The age of detection of DCM, (including LVE and systolic dysfunction) is shown, with onset principally between ages 30-65.

\section{Time between onset of any ECG abnormality and onset of ventricular dysfunction}

One of the key clinical issues we sought to elucidate was the temporal relationship of the onset of ECG abnormalities compared to the onset of ventricular dysfunction. Sixteen subjects (from 11 pedigrees, see methods) with only ECG abnormalities who then developed later ventricular dysfunction were analyzed (Figure 3, Table 5). The median time of detection of ECG abnormalities was 41 years, and the median detection of the first evidence of ventricular dysfunction (LVE, systolic dysfunction, or DCM) was 48 years, a seven year difference. As noted above for the age of detection of ECG abnormalities, similarly we were unable to perform echocardiography on an annual or other set time interval, so the age of onset of LV dysfunction versus the age of detection cannot be known for certain, even though many of these individuals were receiving close follow up from their private physicians with surveillance echocardiography because of their known familial risk for cardiovascular disease and ECG abnormalities.

\section{Discussion}

We undertook this study to derive the most useful and predictive information that can be obtained from ECG and echocardiographic data to inform the care of patients with $L M N A$ cardiomyopathy and their at-risk preclinical or asymptomatic family members who carry their family's $L M N A$ mutation. The 64 individuals who were positive for their family $L M N A$ mutation comprised the study set from which these interpretations have been derived. CSD or arrhythmia occurred either prior to ventricular dysfunction or was present with ventricular dysfunction at the time of initial diagnosis in all cases except one. To gain greater insight into the temporal relationships of the $L M N A$ cardiomyopathy related conduction system disease and arrhythmia relative to the development of ventricular dysfunction, we examined the subset of 16 patients followed from their ages detecting only ECG changes to the ages when LV dysfunction was detected. In those patients we observed a median time difference by log rank analysis of seven years (Figure 3). 
This finding may be helpful to predict the clinical course and therefore to guide clinical surveillance in a $L M N A$ mutation carrier with new evidence of conduction system disease or arrhythmia but prior to the onset of ventricular dysfunction. Recent guidelines ${ }^{5}$ have suggested clinical surveillance every 1-3 years for known mutation carriers at risk for DCM, but based upon this analysis we suggest that with any evidence of new conduction system disease or arrhythmia that clinical cardiovascular surveillance for $L M N A$ mutation carriers be increased to at least annually. This suggestion is especially timely because molecular genetic testing has rapidly proliferated, and a molecular genetic diagnosis of $L M N A$ cardiomyopathy can now be easily achieved in those with new onset DCM with prominent conduction system disease and/or arrhythmia, and clinical and genetic screening and counseling of all at-risk family members of a newly diagnosed proband with $L M N A$ cardiomyopathy has been recommended. ${ }^{5-7}$

It is presently unknown whether LMNA-related conduction system disease or arrhythmia may be amenable to conventional medical treatment with ACE inhibitors, beta blockers or anti-aldosterone agents to prevent progression to ventricular dysfunction. Although such drug therapies have been proposed for DCM of all etiologies ${ }^{23}, L M N A$-specific drug intervention studies to our knowledge have not been reported.

This work also provides guidance for future clinical trials of subjects who have early $L M N A$ cardiomyopathy, for example, for those with ECG abnormalities but with minimal or no evidence of LV dysfunction. In our study the time from ECG abnormalities to the development of LV dysfunction was seven years (Figure 3). Thus, a randomized prevention trial to halt DCM would require an extended follow up. An alternative study design could initiate recruitment and treatment only upon evidence of early ventricular dysfunction. In this regard, we show here that in addition to decreased systolic function, commonly understood to be a sign of cardiomyopathy, that LVE preceding systolic dysfunction may also be considered an early sign of $L M N A$ cardiomyopathy. Also, whether the different presentations (LVE versus systolic dysfunction) relate to genetic background, environmental factors or both remains unknown. Such studies will require larger cohorts of subjects at-risk or with early $L M N A$ cardiomyopathy.

We clarify here that we apply the ' $L M N A$ cardiomyopathy' term to any subject who has shown penetrance of the $L M N A$ genotype, even early conduction system disease well before the onset of systolic dysfunction, LVE or DCM, or its aftermath, heart failure and other advanced disease, as previously proposed for genetic cardiomyopathy nomenclature. ${ }^{24} \mathrm{We}$ also clarify that the genetic term 'penetrance' used here relates to any clinically detectable manifestation of disease in a genetically susceptible individual. Because minor ECG abnormalities are not uncommon in the general population, we note that only 3 of the 39 mutation negative individuals in these families had any ECG abnormalities, and in all cases they were minor. Thus, while one cannot be certain that any minor ECG change in a mutation-positive family member under surveillance for the onset of clinical disease may not have this finding from a non-LMNA related condition, these data suggest that in most cases it is appropriate to presume that ECG changes are an early manifestation of disease. Also, as noted above, the corollary of these observations was that all subjects except one had ECG changes either before or accompanying ventricular dysfunction. This observation suggests that DCM without any ECG changes, especially if advanced or longstanding, would be distinctly unusual with $L M N A$ cardiomyopathy.

\section{Limitations}

Study limitations include its modest size, which precludes any conclusions regarding mutation-specific characteristics, even though to our knowledge this cohort of 103 subjects from 16 pedigrees is second only in size to one other single center $L M N A$ DCM study with 
23 mutations in 27 probands and their 133 relatives. ${ }^{3}$ Larger numbers would improve the certainty of the clinical insights gained here, although our clinical inferences are conservative and congruent with prior literature and related consensus and guideline documents. ${ }^{5-7}$ Also, while most of the clinical information from the largest families (Pedigrees G, J) was derived from our own clinical screening of all willing consented family members, including many who had no detectable disease, ${ }^{10}$ we have not conducted systematic and periodic rescreening of these families so that we may not be aware of all new disease. Further, because of the nature of our study, it is possible that some of the study cohort identified with disease may have had it for some time prior to its detection at our screening events. However, these two families were initially screened in 1998-99, and we have maintained long term follow up with all consented, previously screened members, all of whom were counseled regarding the need for ongoing surveillance screening by their physicians. We have obtained information including the medical records of those who have received new cardiovascular diagnoses, which have all been integrated into this report. Finally, we consider this a preliminary report, as this study design, a family-based gene discovery study, always carries the possibility of an ascertainment bias. It is possible that as larger cohorts of $L M N A$ cardiomyopathy patients are identified more specific insights may emerge, especially since genetic testing is now more commonly available.

\section{Conclusion}

In conclusion, the progression of $L M N A$ cardiomyopathy in almost all cases had ECG abnormalities before the onset of ventricular dysfunction. In a cohort of individuals with only ECG abnormalities, the median time differential to LV dysfunction was seven years. These data may be helpful for informing clinical surveillance of patients and at-risk family members with emerging $L M N A$ cardiomyopathy and for planning $L M N A$ cardiomyopathy clinical trials.

\section{Acknowledgments}

Funding was provided to Dr Hershberger from the National Institutes of Health (HL58626). This work was presented at the American College of Cardiology $61^{\text {st }}$ Annual Sessions Young Investigator Award competition (Dr Brodt).

\section{References}

1. Burkett EL, Hershberger RE. Clinical and genetic issues in familial dilated cardiomyopathy. J Am Coll Cardiol. 2005; 45:969-81. [PubMed: 15808750]

2. Hershberger RE, Siegfried JD. State of the Art Review. Update 2011: clinical and genetic issues in familial dilated cardiomyopathy. J Am Coll Cardiol. 2011; 57:1641-9. [PubMed: 21492761]

3. Pasotti M, Klersy C, Pilotto A, Marziliano N, Rapezzi C, Serio A, et al. Long-term outcome and risk stratification in dilated cardiolaminopathies. J Am Coll Cardiol. 2008; 52:1250-60. [PubMed: 18926329]

4. van Rijsingen IA, Arbustini E, Elliott PM, Mogensen J, Hermans-van Ast JF, van der Kooi AJ, et al. Risk factors for malignant ventricular arrhythmias in lamin a/c mutation carriers a European cohort study. J Am Coll Cardiol. 2012; 59:493-500. [PubMed: 22281253]

5. Hershberger RE, Lindenfeld J, Mestroni L, Seidman CE, Taylor MR, Towbin JA. Genetic evaluation of cardiomyopathy--a Heart Failure Society of America practice guideline. J Card Fail. 2009; 15:83-97. [PubMed: 19254666]

6. Gollob MH, Blier L, Brugada R, Champagne J, Chauhan V, Connors S, et al. Recommendations for the use of genetic testing in the clinical evaluation of inherited cardiac arrhythmias associated with sudden cardiac death: Canadian Cardiovascular Society/Canadian Heart Rhythm Society joint position paper. Can J Cardiol. 2011; 27:232-45. [PubMed: 21459272] 
7. Ackerman MJ, Priori SG, Willems S, Berul C, Brugada R, Calkins H, et al. HRS/EHRA Expert Consensus Statement on the State of Genetic Testing for the Channelopathies and Cardiomyopathies This document was developed as a partnership between the Heart Rhythm Society (HRS) and the European Heart Rhythm Association (EHRA). Heart Rhythm. 2011; 8:130839. [PubMed: 21787999]

8. Wu W, Muchir A, Shan J, Bonne G, Worman HJ. Mitogen-activated protein kinase inhibitors improve heart function and prevent fibrosis in cardiomyopathy caused by mutation in lamin $\mathrm{A} / \mathrm{C}$ gene. Circulation. 2011; 123:53-61. [PubMed: 21173351]

9. Cao K, Graziotto JJ, Blair CD, Mazzulli JR, Erdos MR, Krainc D, et al. Rapamycin reverses cellular phenotypes and enhances mutant protein clearance in hutchinson-gilford progeria syndrome cells. Sci Transl Med. 2011; 3:89ra58.

10. Jakobs PM, Hanson E, Crispell KA, Toy W, Keegan H, Schilling K, et al. Novel lamin A/C mutations in two families with dilated cardiomyopathy and conduction system disease. J Card Fail. 2001; 7:249-256. [PubMed: 11561226]

11. Hershberger RE, Hanson E, Jakobs PM, Keegan H, Coates K, Bousman S, et al. A novel lamin A/ $\mathrm{C}$ mutation in a family with dilated cardiomyopathy, prominent conduction system disease, and need for permanent pacemaker implantation. Am Heart J. 2002; 144:1081-6. [PubMed: 12486434]

12. Parks SB, Kushner JD, Nauman D, Burgess D, Ludwigsen S, Peterson A, et al. Lamin A/C mutation analysis in a cohort of 324 unrelated patients with idiopathic or familial dilated cardiomyopathy. Am Heart J. 2008; 156:161-9. [PubMed: 18585512]

13. Kushner JD, Nauman D, Burgess D, Ludwigsen S, Parks S, Pantely G, et al. Clinical characteristics of 304 kindreds evaluated for familial dilated cardiomyopathy. J Cardiac Failure. 2006; 12:422-29.

14. Li D, Morales A, Gonzalez Quintana J, Norton N, Siegfried JD, Hofmeyer M, et al. Identification of novel mutations In RBM20 in patients with dilated cardiomyopathy. Clin Trans Sci. 2010; 3:90-97.

15. Hershberger RE, Parks SB, Kushner JD, Li D, Ludwigsen S, Jakobs P, et al. Coding sequence mutations identified in MYH7, TNNT2, SCN5A, CSRP3, LBD3, and TCAP from 313 patients with familial or idiopathic dilated cardiomyopathy. Clin Translational Science. 2008; 1:21-26.

16. Vasan R, Larson M, Levy D, Evans J, Benjamin E. Distribution and categorization of echocardiographic measurements in relation to reference limits. The Framingham Heart Study: formulation of a height- and sex-specific classification and its prospective validation. Circ. 1997; 96:1863-1873.

17. Crispell KA, Wray A, Ni H, Nauman DJ, Hershberger RE. Clinical profiles of four large pedigrees with familial dilated cardiomyopathy: preliminary recommendations for clinical practice. J Am Coll Cardiol. 1999; 34:837-47. [PubMed: 10483968]

18. Li D, Parks SB, Kushner JD, Nauman D, Burgess D, Ludwigsen S, et al. Mutations of presenilin genes in dilated cardiomyopathy and heart failure. Am J Hum Genet. 2006; 79:1030-9. [PubMed: 17186461]

19. Cowan J, Li D, Gonzalez-Quintana J, Morales A, Hershberger RE. Morphological analysis of 13 LMNA variants identified in a cohort of 324 unrelated patients with idiopathic or familial dilated cardiomyopathy. Circ Cardiovasc Genet. 2010; 3:6-14. [PubMed: 20160190]

20. Norton N, Li D, Reider MJ, Siegfried JD, Rampersaud E, Zuchner S, et al. Genome-wide studies of copy number variation and exome sequencing identify rare variants in $B A G 3$ as a cause of dilated cardiomyopathy. Am J Hum Genet. 2011; 88:273-282. [PubMed: 21353195]

21. Hershberger RE, Norton N, Morales A, Li D, Siegfried JD, Gonzalez-Quintana J. Coding sequence rare variants identified in MYBPC3, MYH6, TPM1, TNNC1, and TNNI3 from 312 patients with familial or idiopathic dilated cardiomyopathy. Circ Cardiovasc Genet. 2010; 3:155-61. [PubMed: 20215591]

22. Worman HJ, Courvalin JC. How do mutations in lamins A and C cause disease? J Clin Invest. 2004; 113:349-51. [PubMed: 14755330]

23. Hunt SA, Abraham WT, Chin MH, Feldman AM, Francis GS, Ganiats TG, et al. Focused update incorporated into the ACC/AHA 2005 Guidelines for the Diagnosis and Management of Heart Failure in Adults A Report of the American College of Cardiology Foundation/American Heart 
Association Task Force on Practice Guidelines Developed in Collaboration With the International Society for Heart and Lung Transplantation. J Am Coll Cardiol. 2009; 2009; 53:e1-e90. [PubMed: 19358937]

24. Hershberger RE, Morales A, Siegfried JD. Clinical and genetic issues in dilated cardiomyopathy: A review for genetics professionals. Genetics in Medicine. 2010; 12:655-67. [PubMed: 20864896] 


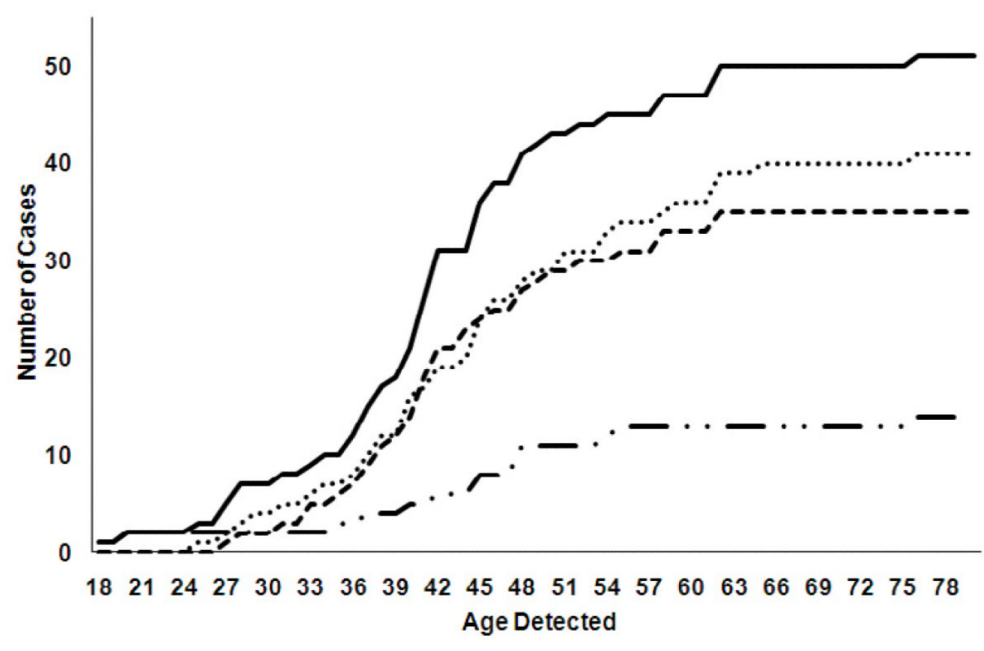

Figure 1. Conduction system disease and arrhythmia

The following clinical categories are shown according to their age of detection. The age of detection of any ECG abnormality (solid line); the age of detection of any diagnosis of arrhythmia (dotted line); the age of detection of conduction system disease (dashed line); the age of detection of His bundle disease (dashed and dotted line). 


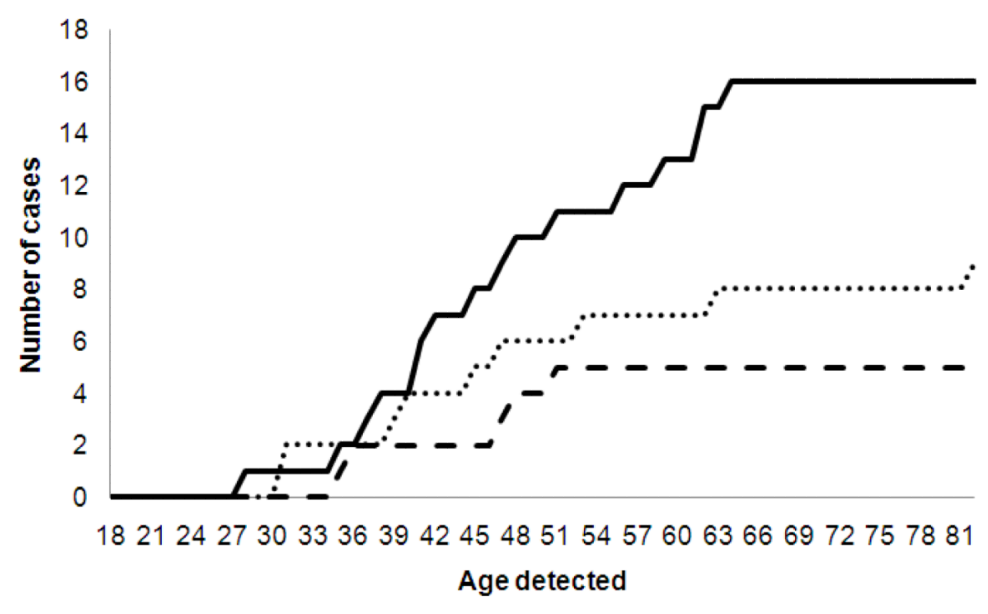

Figure 2. Ventricular dysfunction

The numbers of cases with ventricular dysfunction are shown on the vertical axis and the age detected is shown on the horizontal axis for the following categories: DCM, (solid line); left ventricular enlargement, censored at the time of development of DCM (dotted line); left ventricular systolic dysfunction with no left ventricular enlargement, censored at the time of development of DCM (dashed line). 


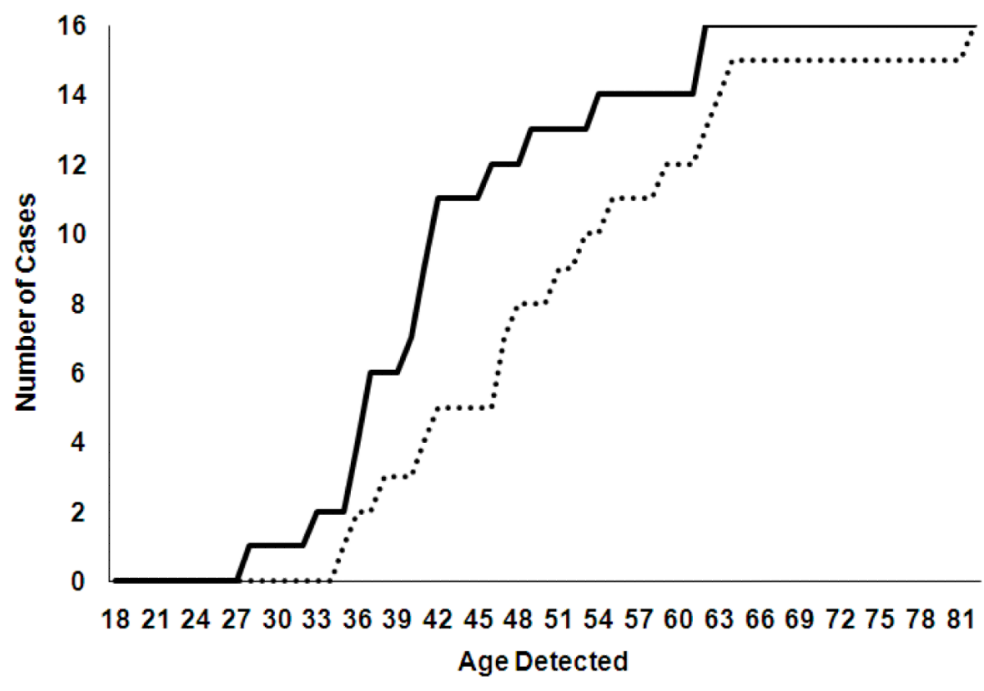

Figure 3. Age of detection of ECG abnormalities in subjects who subsequently developed left ventricular dysfunction

The median age of first detection of any ECG abnormality was 41 years (solid line) and the median age of first detection of any left ventricular dysfunction (left ventricular enlargement, systolic dysfunction without LVE, or DCM) was 48 years (dotted line) is shown. By log rank test the curves were different from one another $(\mathrm{p}=0.016)$. 
Table 2

\section{Summary of Demographic Characteristics}

\begin{tabular}{lcc}
\hline & Mutation Positive & Mutation negative \\
\hline Number of individuals * with genetic diagnosis (\% of total) & $64(62)$ & $39(38)$ \\
Female, n (\%) & $34(53)$ & $20(51)$ \\
Age at first available clinical data, mean \pm SD, (range) & $40.0 \pm 11.2$ & $38.8 \pm 12.4$ \\
& $(18-76)$ & $(18-67)$ \\
BMI, n; mean \pm SD, (range) & $36 ; 26 \pm 4.4$ & $14 ; 27 \pm 3.9$ \\
& $(18-35)$ & $(20-35)$ \\
$\begin{array}{l}\text { Age of last encounter without evidence of cardiovascular } \\
\text { abnormality; n; mean } \pm \text { SD, (range) }\end{array}$ & $12 ; 32.6 \pm 9.1$ & $31 ; 38.6 \pm 11.6$ \\
& & $(19-67)$
\end{tabular}


Table 3

\section{Summary of Ages of Onset of Electrocardiographic Characteristics}

\begin{tabular}{|c|c|c|c|}
\hline All data are shown as $\mathrm{n}$; mean $\pm \mathrm{SD}$ (range) & $\begin{array}{c}\text { Mutation } \\
\text { Positive } \\
\text { n=64 }\end{array}$ & $\begin{array}{c}\text { Mutation } \\
\text { negative } \\
\mathbf{n}=39\end{array}$ & P-value \\
\hline $\begin{array}{l}\text { Age with first available ECG data when accompanied } \\
\text { by LVE, systolic dysfunction or both }\end{array}$ & $\begin{array}{l}8 ; 44.1 \pm 11.2 \\
\quad(28-62)\end{array}$ & 0 & $\mathrm{n} / \mathrm{a}$ \\
\hline Age at first abnormal ECG & $\begin{array}{l}51 ; 42.1 \pm 11.0 \\
(18-76)\end{array}$ & $\begin{array}{l}8 ; 40.4 \pm 16.4 \\
\quad(18-62)\end{array}$ & 0.7844 \\
\hline Age at $\geq 2 \mathrm{ECG}$ abnormalities with first available data & $\begin{array}{l}13 ; 46.1 \pm 11.5 \\
\quad(31-62)\end{array}$ & $\begin{array}{l}2 ; 48.5 \pm 17.7 \\
\quad(36-61)\end{array}$ & 0.7822 \\
\hline $\begin{array}{l}\text { Age of onset of ECG abnormality with normal } \\
\text { ventricular size and function that progressed to DCM }\end{array}$ & $\begin{array}{l}16 ; 43.0 \pm 9.7 \\
\quad(28-62)\end{array}$ & 0 & $\mathrm{n} / \mathrm{a}$ \\
\hline Ages of detection of sinoatrial findings & $\begin{array}{l}35 ; 42.9 \pm 8.9 \\
\quad(27-62)\end{array}$ & $\begin{array}{l}3 ; 51.0 \pm 8.7 \\
(45-61)\end{array}$ & 0.2920 \\
\hline Atrioventricular conduction block (1-3) & $\begin{array}{l}27 ; 41.1 \pm 7.9 \\
\quad(27-63)\end{array}$ & $\begin{array}{l}3 ; 51.0 \pm 8.7 \\
(45-61)\end{array}$ & 0.2260 \\
\hline Sinus node dysfunction & $\begin{array}{l}6 ; 50.2 \pm 9.5 \\
(39-62)\end{array}$ & 0 & $\mathrm{n} / \mathrm{a}$ \\
\hline Placement of Permanent Pacemaker & $\begin{array}{l}27 ; 46.2 \pm 8.9 \\
\quad(31-69)\end{array}$ & $1 ; 62$ & \\
\hline Ages with sinoatrial findings only at presentation & $\begin{array}{l}15 ; 39.8 \pm 8.0 \\
\quad(27-58)\end{array}$ & $\begin{array}{l}2 ; 46.0 \pm 1.4 \\
(45-47)\end{array}$ & 0.0198 \\
\hline Ages at detection of any arrhythmia & $\begin{array}{l}41 ; 45.1 \pm 11.3 \\
\quad(25-76)\end{array}$ & $\begin{array}{l}6 ; 41.7 \pm 19.7 \\
(18-64)\end{array}$ & 0.6812 \\
\hline Atrial fibrillation/flutter & $\begin{array}{l}24 ; 47.0 \pm 9.2 \\
\quad(31-65)\end{array}$ & $\begin{array}{l}2 ; 56.0 \pm 11.3 \\
(48-64)\end{array}$ & 0.1174 \\
\hline Supraventricular tachycardia & $\begin{array}{l}4 ; 35.8 \pm 9.7 \\
(25-49)\end{array}$ & $\begin{array}{l}3 ; 40.7 \pm 17.8 \\
\quad(22-64)\end{array}$ & 0.6904 \\
\hline Premature atrial or ventricular contractions & $\begin{array}{l}22 ; 45.96 \pm 14.5 \\
(27-82)\end{array}$ & $\begin{array}{l}4 ; 43.5 \pm 31.1 \\
\quad(18-62)\end{array}$ & 0.9142 \\
\hline Ventricular tachycardia/fibrillation & $\begin{array}{l}9 ; 55.2 \pm 12.8 \\
(40-82)\end{array}$ & $1 ; 72$ & $\mathrm{n} / \mathrm{a}$ \\
\hline Implantable cardioverter-defibrillator & $\begin{array}{l}9 ; 44.3 \pm 8.2 \\
(33-61)\end{array}$ & 0 & $\mathrm{n} / \mathrm{a}$ \\
\hline Sudden cardiac death & $1 ; 42$ & 0 & $\mathrm{n} / \mathrm{a}$ \\
\hline Ages with arrhythmia only at presentation & $\begin{array}{l}15 ; 41.7 \pm 8.8 \\
\quad(25-62)\end{array}$ & $\begin{array}{l}2 ; 20.0 \pm 2.8 \\
(18-22)\end{array}$ & 0.0028 \\
\hline Ages of detection of His/bundle dysfunction & $\begin{array}{l}14 ; 43.6 \pm 14.4 \\
\quad(18-76)\end{array}$ & $\begin{array}{c}4 ; 47.8 \pm 16.0 \\
(32-62)\end{array}$ & 0.6784 \\
\hline Right bundle branch block & $\begin{array}{c}2 ; 34.0 \pm 19.8 \\
(20-48)\end{array}$ & $\begin{array}{c}4 ; 47.8 \pm 16.0 \\
(32-62)\end{array}$ & 0.4512 \\
\hline Left bundle branch block & $\begin{array}{c}6 ; 49.2 \pm 14.5 \\
\quad(37-76)\end{array}$ & 0 & $\mathrm{n} / \mathrm{a}$ \\
\hline Non-specific or not otherwise specified IVCD & $\begin{array}{c}6 ; 41.3 \pm 13.0 \\
(18-54)\end{array}$ & 0 & $\mathrm{n} / \mathrm{a}$ \\
\hline Ages of His/bundle dysfunction only at presentation & $\begin{array}{c}4 ; 32.0 \pm 15.2 \\
(18-48)\end{array}$ & $1 ; 32$ & $\mathrm{n} / \mathrm{a}$ \\
\hline
\end{tabular}


Table 4

Characteristics of Left Ventricular Enlargement, Systolic Dysfunction or Both (DCM)

\begin{tabular}{|c|c|c|}
\hline All data are shown as n; mean \pm SD (range) & $\begin{array}{l}\text { Mutation } \\
\text { Positive }\end{array}$ & $\begin{array}{l}\text { Mutation } \\
\text { Negative }\end{array}$ \\
\hline Ages of diagnosis of LVE, systolic dysfunction, or both, all subjects & $\begin{array}{c}26 ; 47.6 \pm 12.4 \\
(28-82)\end{array}$ & 0 \\
\hline Those diagnosed without ECG abnormality & $\begin{array}{l}3 ; 39.3 \pm 8.1 \\
(31-45)\end{array}$ & 0 \\
\hline Those with prior known ECG abnormality & $\begin{array}{c}16 ; 51.4 \pm 12.5 \\
(35-82)\end{array}$ & 0 \\
\hline Systolic dysfunction (EF $\leq 50 \%$ ) without LVE & $\begin{array}{c}9 ; 47.9 \pm 16.4 \\
(31-82)\end{array}$ & 0 \\
\hline LVE without systolic dysfunction & $\begin{array}{l}5 ; 43.4 \pm 7.4 \\
\quad(35-51)\end{array}$ & 0 \\
\hline $\mathrm{DCM}^{*}$ & $\begin{array}{c}11 ; 48.7 \pm 11.7 \\
(28-64)\end{array}$ & 0 \\
\hline \multicolumn{3}{|l|}{ Characteristics of DCM at diagnosis } \\
\hline LVEF at diagnosis & $\begin{array}{c}22 ; 39.1 \pm 11.5 \\
(16-50)\end{array}$ & 0 \\
\hline LVE by z-score & $\begin{array}{c}19 ; 3.4 \pm 1.1 \\
(1.78-5.85)\end{array}$ & 0 \\
\hline Ages of subjects receiving a heart transplant & $\begin{array}{l}8 ; 56.0 \pm 6.3 \\
(48-65)\end{array}$ & 0 \\
\hline
\end{tabular}

* One subject was diagnosed with DCM at autopsy and did not have LV size or systolic function available for analysis prior to death 
Table 5

Age at detection of ECG abnormalities and LVE, systolic function, or both, by individual

\begin{tabular}{ccc}
\hline $\begin{array}{c}\text { Age of detection of ECG } \\
\text { abnormality (years) }\end{array}$ & $\begin{array}{c}\text { Age of detection of LVE, } \\
\text { systolic dysfunction, or } \\
\text { both (years) }\end{array}$ & $\begin{array}{c}\text { Difference between } \\
\text { columns A and B (years) }\end{array}$ \\
28 & 35 & 7 \\
33 & 36 & 3 \\
36 & 38 & 2 \\
36 & 41 & 5 \\
37 & 42 & 5 \\
37 & 47 & 10 \\
40 & 47 & 7 \\
41 & 48 & 7 \\
41 & 51 & 10 \\
42 & 53 & 11 \\
42 & 55 & 13 \\
46 & 59 & 13 \\
49 & 62 & 13 \\
54 & 63 & 9 \\
62 & 64 & 2 \\
62 & 82 & 20 \\
\hline
\end{tabular}

